\title{
From pillow to podium: a review on understanding sleep for elite athletes
}

This article was published in the following Dove Press journal:

Nature and Science of Sleep

\section{Shannon O'Donnell Christopher M Beaven Matthew W Driller \\ Health, Sport and Human Performance, University of Waikato, Hamilton, New Zealand}

\begin{abstract}
Sleep is considered vital to human health and well-being, and is critical to physiological and cognitive functioning. Elite athletes experience high training and competition demands, and are often exposed to various factors, situations, and environments that can cause sleep impairments. Previous research has shown that athletes commonly experience sleep loss in the lead up to and following competition, which could have significant impacts on their preparation, performance, and recovery. In particular, the results from previous research show significant reductions in total sleep time ( 1:40 h:min) and significant increases in sleep latency ( $\sim 5$ minutes) following evening competition. Napping is common in both the training and competition setting in athletes; however, research on the effect of napping on physiology and performance is limited. In contrast, research on strategies and interventions to improve sleep are increasing in the athletic population, with sleep hygiene research resulting in significant improvements in key sleep indices. This review investigates the physiological importance of sleep in athletes, current tools to monitor athletes' sleep, the role of sleep for cognitive functioning and athletic performance, the prevalence of sleep disturbances and the potential mechanisms causing sleep disturbances, the role of napping, and different intervention strategies to improve sleep.
\end{abstract}

Keywords: exercise, competition, recovery, athletic performance, chronobiology

\section{Introduction}

As the training requirements for elite athletes increase, the role of adequate recovery becomes an integral component of improving athletic performance between training sessions and competition. ${ }^{1,2}$ The challenge that faces coaches and sport scientists working with elite athletes is to ensure that the intensity of training required to optimize performance does not cause maladaptation, injury, over-reaching, and/or overtraining. ${ }^{3}$ Therefore, in order for athletes to train and compete on a daily and weekly basis, adequate recovery plays a vital role in this adaptation process.

Sleep has been recognized as an essential component in athlete preparation, and it is suggested to be one of the most effective recovery strategies available to athletes, ${ }^{4,5}$ although it is an area often neglected by athletes themselves. ${ }^{6}$ There is growing evidence to show the effects of competition on elite athletes' sleep; however, the direct cause and magnitude of these effects are yet to be determined. Furthermore, in the athletic setting, there is a paucity of data regarding the utilization of napping and the interaction of different hormonal markers with sleep quality and quantity. Therefore, the purpose of this review is to provide a background on the theoretical basis regarding the importance of sleep and its role in recovery and athletic performance. A second-
Correspondence: Matthew W Driller Health, Sport and Human Performance, University of Waikato, Gate I, Knighton Road, Hillcrest, Hamilton, 3216, New Zealand

Tel +64 272929029

Email mdriller@waikato.ac.nz 
ary aim of the review is to evaluate the research literature regarding physiological and performance effects related to sleep, and interventions to improve sleep.

\section{Measuring sleep in athletes}

Several subjective and objective methods have been used to measure sleep in the general population, such as polysomnography, partial polysomnography, ${ }^{7}$ ballistocardiography, ${ }^{8}$ ambulatory polysomnography, ${ }^{9}$ actigraphy, sleep diaries and logs, and sleep questionnaires. While all of these methods are common sleep measures for various sleep research, they may not always be practical in the athlete setting. Measuring sleep in the athletic population is often performed through two commonly used objective measures, polysomnography and actigraphy, and subjective measures including sleep questionnaires, and sleep logs and diaries.

\section{Polysomnography}

Polysomnography is considered the "gold standard" to objectively assess sleep in athletes. ${ }^{10,11}$ Body functions are measured through scalp and skin surface electrode recordings. The electrodes monitor brain activity (electroencephalogram), eye movements (electrooculogram), muscle activity (electromyogram), and cardiac activity (electrocardiogram). ${ }^{11}$ As well as measuring sleep indices, polysomnography allows for the different stages of sleep to be determined. Polysomnography is the primary method used to diagnose and evaluate treatment of sleep disorders and provides the most comprehensive measurement of sleep stages and sleep physiology ${ }^{12}$ against which all other measures of sleep should be validated.

Unfortunately, this method of measuring sleep is not often practical in a sport environment due to the sleep laboratory setting, and the requirement of a specialized trained practitioner to run the testing. It is a more intrusive measuring system and is not reflective of the "real world" setting that researchers experience with elite athletes to gain ecologically valid results.

\section{Actigraphy}

Another commonly used method to objectively assess sleep is through the use of an actigraphy device. Actigraphy is based on small wristwatch devices that monitor movements over extended periods of time, usually in 1-minute data segments. The raw activity scores are translated to sleep-wake scores based on computerized scoring algorithms. ${ }^{11,13-16}$ Actigraphs are used to measure different sleep indices including: total sleep time, sleep efficiency, number of wake episodes, wake after sleep onset, sleep latency, bed time, and wake time. The validation of actigraphy devices has been investigated in relation to polysomnography. ${ }^{17-19} \mathrm{~A}$ review article for comparisons between polysomnography and actigraphy by Ancoli-Israel et a ${ }^{13}$ showed $91 \%$ to $93 \%$ overall agreement in healthy adults aged 20 to 30 years. A recent study by Dunican et a ${ }^{19}$ reported that an actigraph device is suitable for determining sleep onset, sleep duration, and wake time. However, caution should be taken when interpreting sleep latency, sleep efficiency, and wake episodes after sleep onset. The movement, or lack of movement, that occurs during sleep can be mistaken for either wake or sleep, which in turn may over or under estimate sleep indices. Sleep monitoring through actigraphy devices is a practical method in athletes. Numerous research studies indicate that actigraphy is an acceptable method to use in the assessment of sleep and has been generally accepted in the literature. ${ }^{15}$ It is non-invasive to the individuals, portable, is more accessible for athletes, and is usable in "normal" sleeping environments.

\section{Sleep questionnaires and diaries}

Sleep logs and diaries have been widely used to evaluate both sleep quality and quantity, ${ }^{20}$ to give a participant's perception of bed and wake times and quality of their sleep. Caia et al $^{20}$ investigated self-perceived sleep in comparison to sleep estimated via actigraphy in 63 professional male rugby league athletes. From the 641 nights of sleep monitoring, results showed a very large, positive $(r=0.85)$ correlation between self-perceived sleep duration and actual sleep duration measured via the actigraph. A mean bias showed perceived sleep was over-estimated by an average of 19.8 minutes as shown in Table 1. Therefore, the use of subjective measures to monitor sleep duration is acceptable when objective monitoring cannot be used. Furthermore, using sleep questionnaires and diaries in combination with actigraphy where possible may increase the accuracy of the sleep date. ${ }^{14}$

The Pittsburg Sleep Quality Index (PSQI) ${ }^{21}$ and the Epworth Sleepiness Scale (ESS) ${ }^{22}$ have been widely used in sleep research. However, it has been suggested that these questionnaires may not be sensitive enough to determine the unique challenges and differences in athletes' sleep habits. ${ }^{23}$ Two athlete-specific sleep questionnaires have recently been developed, which are more reflective to the environment and factors that athletes encounter in regards to their sleep..$^{23,24}$ Samuels et $\mathrm{al}^{24}$ developed the Athlete Sleep Screening Questionnaire (ASSQ), which is a 15-item questionnaire with 6 main areas: total sleep time, insomnia, sleep quality, chronotype, sleep-disordered breathing, and travel disturbances. 
Table I Studies examining modes of sleep monitoring in athletes

\begin{tabular}{|c|c|c|c|c|}
\hline Study & Subjects (n) & Fitness status & Sleep monitoring modes & Results" \\
\hline Caia et $\mathrm{al}^{20}$ & 63 & $\begin{array}{l}\text { Professional rugby } \\
\text { league athletes }\end{array}$ & $\begin{array}{l}\text { Perceived sleep duration vs } \\
\text { actigraphy device }\end{array}$ & Very large, positive correlation $(r=0.85)$ \\
\hline Driller et $\mathrm{al}^{15}$ & 11 & Recreational athletes & Inter-device reliability of an actigraph & $\begin{array}{l}\text { NS } \\
\text { High to very high ICC }(0.80 \text { to }>0.90)\end{array}$ \\
\hline Driller et al ${ }^{16}$ & 13 & Recreational athletes & $\begin{array}{l}\text { Actigraphy device between dominant } \\
\text { vs non-dominant wrist }\end{array}$ & $\begin{array}{l}\text { NS } \\
\text { High to very high correlations }(r=0.76 \text { to }>0.90)\end{array}$ \\
\hline Driller et $\mathrm{a}^{23}$ & 564 & $\begin{array}{l}\text { Athletes (242) } \\
\text { Non-athletes (322) }\end{array}$ & $\begin{array}{l}\text { Athlete Sleep Behavior } \\
\text { Questionnaire vs Pittsburg Sleep } \\
\text { Quality Index, Sleep Hygiene Index, } \\
\text { and Epworth Sleepiness Scale }\end{array}$ & $\begin{array}{l}\text { Moderate to large correlations ( } r=0.38-0.69) \\
\text { between Athlete Sleep Behavior Questionnaire } \\
\text { and the three other questionnaires } \\
\text { ICC retest } 7 \text { days }(0.87) \text { for the Athlete Sleep } \\
\text { Behavior Questionnaire }\end{array}$ \\
\hline Samuels et $\mathrm{al}^{24}$ & 58 & Highly trained & $\begin{array}{l}\text { Athlete Sleep Screening } \\
\text { Questionnaire vs Pittsburg Sleep } \\
\text { Quality Index }\end{array}$ & $\begin{array}{l}\text { High test-retest correlations }(r=0.90) \text { for } \\
\text { Athlete Sleep Screening Questionnaire }\end{array}$ \\
\hline Sargent et al ${ }^{91}$ & 16 & $\begin{array}{l}\text { Highly trained } \\
\text { endurance cyclists }\end{array}$ & $\begin{array}{l}\text { Polysomnography vs activity } \\
\text { monitors }\end{array}$ & Good agreement (81\%-90\%) \\
\hline
\end{tabular}

Notes: "Statistically significant $(p<0.05)$.

Abbreviations: ICC, intraclass coefficient correlation; NS, non-significant.

The ASSQ acts as a clinical tool with thresholds that indicate sleeping disorders. Driller et a ${ }^{23}$ developed the Athlete Sleep Behavior Questionnaire (ASBQ), consisting of an 18-item questionnaire to be used by practitioners and researchers when working with elite athletes. In contrast to the ASSQ, the ASBQ is more of a practical tool used by coaches and practitioners to identify maladaptive sleep hygiene behaviors rather than sleep disorders. Results showed significant differences between athletes $(n=242)$ and non-athlete $(n=322)$ groups for the ASBQ global score.

\section{Physiology of sleep for athletes}

The human body is fundamentally based upon rhythmicity, with circadian rhythms observed in the majority of human physiological variables. ${ }^{6,25}$ One of the fundamental rhythms characterized by the 24-hour day-night cycle is the sleepwakefulness cycle, which is of significant importance to human circadian rhythms. ${ }^{26-28}$ In a review article by Halson, ${ }^{11}$ sleep was defined as a reversible behavioral state in which an individual is perceptually disengaged from and unresponsive to the environment. The sleep-wakefulness cycle enables the body to recover from prior states of wakefulness allowing an individual to awaken feeling alert. ${ }^{29}$

A number of hormonal responses take place in the lead up to and during sleep. One important hormone relating to athletic recovery is growth hormone. Growth hormone is necessary for body restoration, and plays an important role in muscle growth and repair. ${ }^{29-31}$ Muscle growth, repair, and bone building are vital for athletic recovery following strenuous training and competition. It has been reported that $95 \%$ of the daily production of growth hormone is released from the pituitary gland in the endocrine system during non-rapid eye movement (NREM) sleep stage three, ${ }^{6}$ therefore, NREM sleep is considered the time in which the body actively repairs and restores itself. ${ }^{10,29,32}$

Exercise is a physiological stressor activating the hormonal systems, namely, corticotropin-releasing hormone (the hypothalamic), adrenocorticotropic hormone (the anterior pituitary), and adrenal glucocorticoids..$^{33}$ Two of the main hormones often studied in relation to physical activity are cortisol and testosterone. Cortisol is a steroid hormone produced and released in the adrenal gland. ${ }^{34}$ It plays a central role in the physiological and behavioral response to physical activity, as well as important metabolic functions and regulation of the immune system. ${ }^{33,34}$ Testosterone is also a steroid hormone, and is associated with physiological responses to exercise, specifically contributing in muscular hypertrophy following resistance training. ${ }^{35}$ The balance and timing of anabolic (testosterone) and catabolic (cortisol) hormones are considered essential to muscle adaptation, specifically muscle growth. ${ }^{36,37}$ It has been reported that cortisol and testosterone both follow a circadian rhythm, and are affected following sleep deprivation, with an increase in the secretion of cortisol and changes in the pattern of rhythmic secretion of testosterone, ${ }^{38}$ which can affect the anabolic and catabolic balance. Furthermore, stress is a characteristic aspect of 
sports competition, regarded as a psychophysiological process, affecting athletes both cognitively and physiologically. ${ }^{39}$ It should also be acknowledged that hormonal profiles might be different in athletes and non-athletes; this could be both at rest or in response to exercise. ${ }^{40}$

Although previous studies have assessed the effect of sporting competition on sleep, ${ }^{41-44}$ few studies have examined the possible mechanisms contributing to poor sleep during competition. Research from our laboratory ${ }^{45}$ examined the stress response and subsequent sleep response following an evening netball match and netball match simulated training session in 10 elite female netball athletes. Results showed significantly higher $(p<0.05)$ levels of cortisol immediately post and at 22:00 $\mathrm{h}$ on the match day compared to the match simulated training session $(0.700$ and $0.165 \mu \mathrm{g} / \mathrm{dL}$, respectively). Subsequent significant reductions in total sleep time and sleep efficiency were observed following the match (6:03 h:min and $74.4 \%$, respectively) compared to training (8:01 h:min and $82.1 \%$, respectively). Similarly, Juliff et a ${ }^{46}$ investigated the physiological mechanisms for impaired sleep. A total of 12 elite female netball athletes had their sleep monitored through actigraphy, along with psychometric and physiological variables measured between a game day and rest day. Results showed a statistically significant reduction $(p<0.05)$ reduction in both sleep duration and sleep efficiency following the game day compared to rest day. Additionally, cortisol levels were significantly higher immediately post-game and 1 hour post-game compared to a rest day. A decrease in sleep efficiency was strongly associated with an increase in hyperarousal scores $(r=-0.611)$. Furthermore, a study by Swinburne et $\mathrm{al}^{47}$ examined the effect of a sleep extension period on sleep, performance, immunity, and stress in rugby players. Results indicated improved sleep indices, and beneficial changes in cortisol expression and reaction time performance.

Previous reviews into the literature on sleep and stress responses have indicated this relationship to be complex, with many contributing factors. ${ }^{48,49} \mathrm{~A}$ study by Omisade et al ${ }^{50}$ examined the levels of cortisol and leptin (hormone associated with feelings of satiety) in 15 young women following acute sleep restriction of a 3-hour total sleep period. The results showed that morning cortisol levels were significantly increased following the sleep restriction period compared to baseline. Moreover, levels of cortisol following the sleep restriction period took significantly longer to decline over the day than baseline measures. Morning leptin levels showed a significant increase in sleep restriction from baseline. The results from this study indicate one night of sleep restriction disturbs cortisol levels, which could have an effect on subsequent sleep patterns ${ }^{51}$ and metabolic function..$^{52,53}$

Exercise may also heavily influence the role of melatonin biorhythms, as previous research has shown the secretion of melatonin levels to be suppressed following exercise. ${ }^{54,55}$ It is thought that physical exercise may induce circadian system synchronization, therefore modifying melatonin levels. ${ }^{55} \mathrm{Mel}-$ atonin is a hormone that is synchronized from environmental cues, contributing to the initiation of sleep in the circadian system. ${ }^{55}$ Previous research investigating melatonin and exercise has reported conflicting results, with both increases and decreases in melatonin levels observed following exercise. ${ }^{55}$ A study by Buxton et $\mathrm{al}^{56}$ assessed the melatonin response following differing intensity and durations of nocturnal exercise in eight moderately trained males. Results reported a phase delay of plasma melatonin secretion following both a 3-hour low-intensity exercise session (63 minutes) and a 1-hour high-intensity exercise session (55 minutes) compared to a baseline non-exercising condition. It has been summarized in the Escames et al's ${ }^{55}$ review that the consequence of exercise on melatonin rhythms varies depending on the intensity of lighting, the proximity of exercise to the onset or decline of the circadian production of melatonin, the length and intensity of the exercise, and the time of day.

\section{Sleep and cognitive performance in athletic populations}

In regards to cognitive function, rapid eye movement (REM) sleep has a vital role with restorative benefits for cognition. ${ }^{57,58}$ Similar EEG activity patterns have been observed between REM sleep and wake periods, and it has been proposed that the high neural activity during REM sleep is associated with memory consolidation and learning of motor skills. ${ }^{6,29,30,59}$ The quantity and quality of sleep the night following a memory task have been positively correlated to the extent of recall and retention the next day. ${ }^{60}$ Elite athletes experience high levels of cognitive requirements in their sports, and the demand for ongoing motor learning and cognitive process is high. ${ }^{61}$

Several studies have investigated the effect of sleep deprivation, both partial and total, on cognitive performance. A significant amount of evidence suggests that sleep deprivation adversely affects cognitive performance. ${ }^{62} \mathrm{~A}$ study by Taheri and Arabameri ${ }^{63}$ looked at the effect of sleep deprivation on choice reaction time and anaerobic power of college athletes. The cognitive measure in the study showed a significant increase in reaction time reported from baseline to post-sleep 
deprivation (244 milliseconds pre-sleep deprivation, 282 milliseconds post-sleep deprivation). A study by Edwards and Waterhouse ${ }^{64}$ assessed the effects of partial sleep deprivation on the accuracy and consistency of throwing darts in 60 participants, with results showing decreases in alertness and accuracy. Furthermore, Reyner and Horne ${ }^{65}$ examined the effect of sleep restriction on the serving accuracy of tennis players, with results indicating significant impairments in serving accuracy following the sleep restriction period (Table 2). A study by Ben Cheikh et al ${ }^{66}$ examined the effect of one night's sleep deprivation on selective attention and isometric force in karate athletes, with results indicating significant differences following the one night's sleep deprivation period in the activation processes of selective attention and maximal isometric strength.

Although it is unlikely that athletes will experience sleep deprivation to the extent used in the previous studies, an athlete's sleep can still be disrupted for a number of reasons, which can impact their cognitive performance. In team sports, the ability to make fast and accurate decisions is just as important as executing skills efficiently during a match. ${ }^{67}$ Therefore, the role of sleep in the sleep-wake cycle is fundamental for both the physical and cognitive repair and recovery of an individual. It is clear that the disruption of the sleep-wake cycle can have significant effects on both mental and physical performance in various settings. ${ }^{26}$

\section{Sleep and sports performance}

Elite athletes are facing more intensive physical training loads, competition loads, and high levels of mental stress on a regular basis, ${ }^{68-70}$ resulting in several factors that could have an influence on sleep disturbances. These may include scheduling of competition, ${ }^{71}$ increased psychological stress, "social" requirements, a disruption from light and noise, ${ }^{72,73}$ and increased muscle pain and tension following training and competition. ${ }^{11}$ Increased core temperature following training and competition ${ }^{74,75}$ may also potentially disrupt the thermophysiological cascade that initiates sleep. ${ }^{76,77}$

A study by Leeder et $\mathrm{al}^{3}$ examined the sleep duration and quality of 46 elite athletes participating at a national level in a range of sports. Results from the study showed that, although not statistically significant, athletes' sleep duration was less than the control group (6:55 h:min and 7:11 h:min, respectively). Results showed a significant difference between the athletes and control, for both sleep latency (18.2 minutes and 5.0 minutes, respectively) and sleep efficiency $(80.6 \%$ and $88.7 \%$, respectively). Furthermore, the study by Lastella et al ${ }^{67}$ investigated the sleep-wake behavior of 124 elite athletes from individual and team sports. The results from the study reported that, on average, athletes from individual sports obtained 6.5 hours of sleep per night and athletes from team sports obtained 7.0 hours of sleep per night. Moreover, it was reported that athletes from individual sports had a higher napping frequency than athletes from a team sport. A study by Hoshikawa et $\mathrm{al}^{78}$ investigated the sleep of 817 Japanese athletes, with results showing a mean time in bed of 7:29 h:min, and 229 (28\%) athletes showing a PSQI global score above the clinical criteria for poor sleep quality. Similarly, a study by Mah et $\mathrm{al}^{79}$ examined the sleep of 628 collegiate student-athletes, with results showing $42.4 \%$ of athletes experiencing poor sleep quality, and $39.1 \%$ of athletes regularly obtaining $<7$ hours of sleep per night.

Another important area important for future research is how sleep is affected by athletic competition, ${ }^{41-44,80}$ considering the increased stress imposed by competition scheduling as more sports transition into the professional era. Research from our laboratory ${ }^{80}$ assessed the sleep-wake behavior prior to, on the night of, and following competition in 11 elite female netball athletes. The results showed total sleep time was significantly reduced on the night of competition (6:46 h:min),

Table 2 Studies examining sleep interventions on cognitive performance in athletes

\begin{tabular}{|c|c|c|c|c|c|}
\hline Study & $\begin{array}{l}\text { Subjects } \\
\text { (n) }\end{array}$ & Fitness status & Sleep intervention & Performance outcome & Results $^{\#}$ \\
\hline \multirow[t]{2}{*}{ Edwards and Waterhouse ${ }^{64}$} & $60^{\mathrm{a}}$ & Dart players & 4-hour delayed bed time & Dart throwing accuracy & $\downarrow^{\#}$ \\
\hline & & & & Alertness & $\downarrow \#$ \\
\hline \multirow[t]{2}{*}{ Jarraya et al ${ }^{102}$} & $12^{\mathrm{a}}$ & Handball goalkeepers & Partial SD, 4-5 hours sleep & Reaction time & 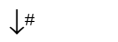 \\
\hline & & & obtained & Stroop test & $\downarrow \#$ \\
\hline Mah et $\mathrm{al}^{83}$ & $\mathrm{I} \mathrm{I}^{\mathrm{a}}$ & College basketball athletes & Sleep extension by 2 hours & Reaction time & 个\# \\
\hline Reyner and Horne ${ }^{65}$ & $16^{a}$ & Trained tennis players & $2-2.5$ hours delayed bed time & Tennis serving accuracy & $\downarrow \#$ \\
\hline Scott et $\mathrm{al}^{103}$ & $6^{\mathrm{a}}$ & Recreational athletes & Total SD 30 hours & Reaction time & $\downarrow \#$ \\
\hline Taheri and Arabameri ${ }^{63}$ & $18^{a}$ & Trained college students & Total SD 24 hours & Choice reaction time & $\downarrow^{\#}$ \\
\hline
\end{tabular}

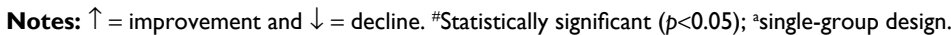

Abbreviation: SD, sleep deprivation. 
compared to the night prior to competition (8:31 h:min) and remained significantly reduced on the night following competition (7:23 h:min) as shown in Table 3. A significant difference was observed for sleep onset time between all three nights, with an average sleep onset time of 23:57 pm on the night of competition. A study by Shearer et $\mathrm{al}^{43}$ assessed the sleep of 28 male rugby union players following a game and a reference night, with results showing a significant reduction in sleep following the game (6:02 h:min) compared to the reference night (7:04 h:min,). Similarly, both Fullagar et $\mathrm{al}^{41}$ and Sargent and Roach $^{42}$ reported significant reductions in sleep on the night of competition in 16 elite male football athletes and 22 male Australian rules football athletes (5:43 h:min and 5:18 h:min, respectively). Furthermore, a study by Juliff et $\mathrm{al}^{44}$ investigated sleep patterns of 42 female netball athletes across a 6-day competition. The results reported that athletes' sleep was reduced by 29 minutes following the night games compared to the afternoon games. Interestingly, a strong correlation $(r=-0.68)$ indicated that longer sleep durations throughout the competition were associated with a higher tournament finishing place. These studies demonstrate that both male and female athletes experience impaired sleep following competition; therefore, suitable interventions should be used to alleviate these issues (Table 3). It has also been shown that changes to the training environment also affect athletes' sleep habits. Pitchford et $\mathrm{l}^{81}$ investigated the effect of a change in training environment from an 8-day home to camp period in 19 Australian rules football players, with results indicating the camp environment compromised sleep quality compared to the home environment.

Given the significant changes to athlete's sleep habits around competition periods, understanding factors that could contribute to these is important. One such factor is the use of caffeine as a stimulus on competition days. A study by Dunican et $\mathrm{l}^{82}$ evaluated caffeine use in 20 elite rugby union players in a Super Rugby competition game and its relationship to post-game sleep. Results showed a significant increase in salivary caffeine levels post-game to pre-game $(2.35 \mu \mathrm{g} /$ $\mathrm{mL}$ ), which may have contributed to the reduced sleep duration observed on the night of competition.

The majority of sleep research has evaluated the effect of sleep deprivation (partial and total) and the accumulation of sleep debt on cognitive function, mood levels, daytime sleepiness, and physical performances. ${ }^{83}$ Few previous studies have examined the role of sleep extension and the subsequent benefits (Table 4). A study by Mah et al ${ }^{83}$ investigated the effect of sleep extension on the athletic performance of 11 college basketball players. The total sleep time duration of the athletes showed a significant improvement by 110 minutes from baseline to the sleep extension period. In regards to the athletic performance, all three variables (282 feet sprint time, free throws out of 10, and 3-point field goals out of 15)

Table 3 Studies examining sleep and exercise in athletes

\begin{tabular}{|c|c|c|c|c|c|c|}
\hline \multirow[t]{2}{*}{ Study } & \multirow[t]{2}{*}{ Subjects (n) } & \multirow[t]{2}{*}{ Sport and fitness status } & \multirow[t]{2}{*}{ Protocol } & \multicolumn{3}{|c|}{ Results\# } \\
\hline & & & & TST & SE\% & SL \\
\hline \multirow[t]{2}{*}{ Juliff et $\mathrm{al}^{46}$} & $42^{\mathrm{a}}$ & Netball & Evening competition vs afternoon competition & $\downarrow^{\#}$ & NR & NR \\
\hline & & National & & & & \\
\hline \multirow[t]{2}{*}{ Fullagar et al ${ }^{41}$} & $16^{\mathrm{a}}$ & Football & Evening competition vs day training & $\downarrow^{\#}$ & NR & $\downarrow \#$ \\
\hline & & Elite & & & & \\
\hline \multirow[t]{2}{*}{ Lastella et al ${ }^{67}$} & $21^{\mathrm{a}}$ & Endurance cyclists & Competition vs baseline & $\downarrow^{\#}$ & NS & NS \\
\hline & & Elite & & & & \\
\hline Oda and Shirakawa ${ }^{74}$ & $12^{\mathrm{a}}$ & Healthy adults & High-intensity evening exercise vs non-exercise & $\downarrow^{\#}$ & $\downarrow^{\#}$ & $\downarrow \#$ \\
\hline \multirow[t]{2}{*}{ O'Donnell et $\mathrm{a}^{45}$} & $1 \mathrm{I}^{\mathrm{a}}$ & Netball & Evening competition vs night prior & $\downarrow^{\#}$ & NS & NS \\
\hline & & Elite & vs night following & $\downarrow^{\#}$ & NS & NS \\
\hline \multirow[t]{2}{*}{ O'Donnell et al ${ }^{80}$} & $10^{\mathrm{a}}$ & Netball & Evening game vs evening training & $\downarrow^{\#}$ & $\downarrow^{\#}$ & NS \\
\hline & & Elite & vs control & $\downarrow^{\#}$ & $\downarrow^{\#}$ & $\downarrow \#$ \\
\hline \multirow[t]{3}{*}{ Richmond et al ${ }^{104}$} & $10^{\mathrm{a}}$ & Australian Football League & Evening games vs baseline & & & \\
\hline & & Elite & Home & $\downarrow^{\#}$ & NS & NS \\
\hline & & & Away & $\downarrow^{\#}$ & NS & NS \\
\hline \multirow[t]{2}{*}{ Sargent and Roach ${ }^{42}$} & $22^{\mathrm{a}}$ & Australian Football League & Evening game vs day game & $\downarrow^{\#}$ & NS & NS \\
\hline & & Elite & & & & \\
\hline \multirow[t]{2}{*}{ Shearer et al ${ }^{43}$} & $28^{a}$ & Rugby Union & Evening home game vs reference night & $\downarrow^{\#}$ & NS & NS \\
\hline & & National & & & & \\
\hline
\end{tabular}

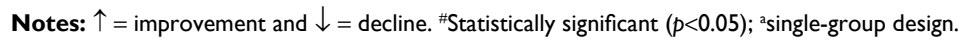

Abbreviations: NR, not reported; NS, non-significant; SE\%, sleep efficiency; SL sleep latency; TST, total sleep time. 
significantly improved following the sleep extension period. The mean reaction time in the morning and evening also significantly decreased over the sleep extension period with improvements in daytime sleepiness and mood.

An important area for future research that is often overlooked is the relationship between sports injuries and both sleep quality and quantity. As sleep deprivation has been shown to reduce reaction time, cognitive function, and affect mood, it is proposed that this could be associated with an increased risk of sporting injuries. ${ }^{84} \mathrm{~A}$ recent study by Milewski et al ${ }^{84}$ has investigated chronic lack of sleep and the subsequent association with increased sports injuries in 112 adolescent athletes over a 21-month period. Of the 112 participants, 64 athletes (57\%) sustained a total of 205 injuries over the course of monitoring. Relative risk of injury by Poisson regression showed that the strongest predictor of injury was $<8$ hours sleep per night. The results reported that $65 \%$ of athletes who reported sleeping $<8$ hours of sleep per night experienced an injury over the 21 months of monitoring. It was also reported that athletes who slept on average $<8$ hours per night had 1.7 times greater risk of being injured than the athletes who obtained $\geq 8$ hours of sleep per night.

Elite athletes experience disturbance to their sleep from a variety of variables as illustrated in the previous research. The improvements shown in performance, reaction time, injury risk, and mood following a sleep extension intervention provide a strong rationale for future research targeting sleep hygiene to enhance athletic performance.

\section{Napping and sports performance}

Napping has been reported by Petit et $\mathrm{al}^{85}$ as a behavioral measure to alleviate sleep debt, with the afternoon being the most frequent time that napping occurs, likely due to the dip in circadian alertness ${ }^{86}$ It has been highlighted in previous research, in particular by Davies et a ${ }^{87}$ and Petit et al, ${ }^{85}$ that there are two "ideal" time durations for a nap. The authors would suggest that nap durations of less than 20 minutes may be preferential, to reduce the likelihood of waking up during slow-wave sleep, thereby increasing sleep intertia. ${ }^{85}$ Alternatively, 90 minutes is also considered optimal as this allows a complete sleep cycle (NREM and REM) to occur, reducing the effects of sleep inertia. ${ }^{87}$ Although limited, previous research ${ }^{67,88,89}$ has reported the prevalence of daytime naps in the athletic training setting. According to Lastella et al, ${ }^{67}$ team sport athletes' nap frequency was $11 \%$ over a 7 -night period, with a mean duration of 0:59 $\pm 1: 02 \mathrm{~h}: \mathrm{min}$. Additionally, Thornton et a ${ }^{89}$ reported of the 31 professional male rugby league athletes, $83 \%$ choose to nap during a 2 -week training camp, with an average of 6.3 naps each.

A study by Waterhouse et al ${ }^{86}$ investigated the effect of a lunchtime nap following a partial (4 hours) sleep deprivation in 10 healthy male participants. Results from the study reported a significant improvement in both the $2 \mathrm{~m}(p=0.03)$ and $20 \mathrm{~m}$ sprint following the 30 -minute nap condition compared to a no-nap condition. Research from our laboratory ${ }^{90}$ assessed the effect of match-day napping on perceptual and performance indices in 14 elite female athletes throughout two competitive netball seasons. The results reported a

Table 4 Studies examining strategies to improve sleep indices in athletes

\begin{tabular}{|c|c|c|c|c|c|}
\hline Study & Subjects (n) & Sport and fitness status & Sleep intervention & Measures & Results ${ }^{\#}$ \\
\hline \multirow[t]{3}{*}{ Duffield et al ${ }^{100}$} & $8^{\mathrm{a}}$ & Tennis & Sleep hygiene & TST & Large effect $(d=2.60) \uparrow \mathrm{NS}$ \\
\hline & & Professional & recommendations & SE (\%) & Moderate effect $(d=0.90) \uparrow \mathrm{NS}$ \\
\hline & & & & SL & Small effect $(d=0.23) \uparrow \mathrm{NS}$ \\
\hline \multirow[t]{3}{*}{ Fullagar et $\mathrm{al}^{41}$} & $20^{\mathrm{a}}$ & Football & Sleep hygiene strategy & TST & $\uparrow \#$ \\
\hline & & Highly trained & & SE (\%) & NS \\
\hline & & & & SL & NS \\
\hline \multirow[t]{3}{*}{ Mah et $\mathrm{al}^{79}$} & $1 I^{\mathrm{a}}$ & Basketball & Sleep extension ( 2 hours) & Sprint & $\uparrow \#$ \\
\hline & & Trained & & Free throws & $\uparrow \#$ \\
\hline & & & & Three-point goals & $\uparrow \#$ \\
\hline O'Donnell and & $26^{\mathrm{a}}$ & Netball & Sleep hygiene education & TST & Small effect $(d=0.39) \uparrow^{\#}$ \\
\hline \multirow[t]{2}{*}{ Driller ${ }^{99}$} & & Elite & session & SE (\%) & Small effect $(d=0.26) \uparrow \mathrm{NS}$ \\
\hline & & & & SL & Small effect $(d=-0.27) \uparrow N S$ \\
\hline Tuomilehto & $40^{\mathrm{a}}$ & Ice hockey & Sleep counseling & Perceived sleep & $83 \%$ reported benefit $\uparrow \#$ \\
\hline et $a^{69}$ & & professional & & quality & \\
\hline Van Ryswsk & $25^{\mathrm{a}}$ & Football & Education session & Perceived & \\
\hline \multirow[t]{2}{*}{ et $\mathrm{al}^{101}$} & & Trained & & TST & 个\# \\
\hline & & & & SE (\%) & $\uparrow \#$ \\
\hline
\end{tabular}

Notes: $\uparrow=$ improvement and $\downarrow=$ decline. "Statistically significant $(p<0.05)$; ${ }^{\text {s }}$ ingle-group design.

Abbreviations: NS, non-significant; SE, sleep efficiency; SL, sleep latency; TST, total sleep time. 
significant increase in peak jump velocity from a countermovement squat jump following a 20-minute or less nap compared to a no nap. Further, coach performance ratings of player performance during competitive matches were significantly higher following a 20-minute or less nap compared to athletes that had not napped.

Furthermore, a study by Davies et $\mathrm{al}^{87}$ investigated the sleep quality of a nap following a morning endurance training session in six trained male athletes. The participants completed a standardized 90-minute endurance training session in the morning followed by a 90-minute nap at either 1 hour or 2 hours post-training session. Their results indicated that a nap at $11: 30 \mathrm{~h}$ as opposed to $10: 30 \mathrm{~h}$ showed a significantly greater amount of slow-wave sleep (13.7 minutes vs 6.9 minutes). As mentioned previously, slow-wave sleep is notable as being recuperative, and due to the release of growth hormone, may aid in the physiological recovery of an athlete.

To our knowledge, our study ${ }^{90}$ is the only published research that examines the effect of a pre-competition nap on subsequent performance in elite athletes, although anecdotal evidence suggests that napping occurs on the day of competition. It is hypothesized that sleep behavior, in particular reduced sleep, on the night prior to competition may be a reason that athletes utilize pre-competition naps prior to their performance to alleviate the sleep debt from the previous night. According to Lastella et al, ${ }^{91} 68 \%$ of athletes in their study reported experiencing poorer than normal sleep on the night prior to competition, resulting in a total sleep time of 5 hours 51 minutes on average. Furthermore, a recent study by Juliff et $\mathrm{al}^{4}$ reported $64 \%$ of the 283 elite athletes sampled indicated they had slept worse than usual in the night(s) prior to an important competition, with $42.1 \%$ reporting an increase in daytime sleepiness as a consequence of sleep disruption.

\section{Sleep hygiene education and sports performance}

Sleep hygiene is described as practicing behaviors that facilitate sleep and avoiding behaviors that interfere with sleep. ${ }^{11,92,93}$ Sleep hygiene education has been used as a tool to educate individuals on the fundamental aspects of sleep and practical applications to improve sleep quality and quantity. Sleep hygiene education may include aspects of lifestyle and behavior as well as environmental factors that influence sleep such as light, noise, and temperature. ${ }^{94-96}$

The use of education on sleep hygiene has been proven to improve sleep quality and quantity in previous research, within different populations and contexts (Table 4). ${ }^{94-97}$
However, sleep hygiene interventions and education research has only been a recent development in the athletic setting. A study by Fullagar et $\mathrm{al}^{98}$ investigated the effect of an acute sleep hygiene strategy following an evening soccer match in 20 male athletes. The sleep hygiene strategy involved temperature and light controlled rooms, with restricted technological device use prior to lights out, and was implemented following the athlete's post-match routines. Results showed that the athletes' total sleep time was significantly greater (1:39 h:min) in the group following the sleep hygiene strategy when compared to the no sleep hygiene strategy group. Similarly, research from our laboratory ${ }^{99}$ examined the effect of a 1-hour sleep hygiene education session in 26 elite female netball athletes from a baseline week to 1 week after the session. The results show a significant increase in total sleep time of 22.3 minutes in the week following the sleep hygiene education session compared to baseline.

A study by Duffield et al ${ }^{100}$ evaluated the effect of a mixed recovery intervention, including sleep hygiene recommendations in eight professional male tennis players. Similarly to Fullagar et al's ${ }^{98}$ protocol, restricted electronic stimulants were implemented 30 minutes prior to lights out, and the athletes slept in a temperature controlled condition. The authors reported increased time in bed and minutes spent asleep following the sleep hygiene condition, combined with the other recovery interventions, compared to the control condition. Furthermore, Van Ryswyk et al ${ }^{101}$ investigated the effect of a 6-week sleep hygiene optimization program in 25 male football athletes. The athletes were provided with a 1-hour sleep hygiene education session at the start of the study period. Feedback and progress was provided to the athletes once per week for a 6-week period, with a follow-up mid-program education session. The results from Van Ryswyk et al's ${ }^{101}$ study also demonstrated significant increases in total sleep time and sleep efficiency at the conclusion of the 6-week sleep hygiene education intervention compared to baseline values.

The mentioned studies ${ }^{71,99-101}$ show a positive relationship with sleep indices and the use of sleep hygiene intervention and education sessions, highlighting the importance of sleep hygiene in the athletic population for both team and individual sport athletes.

\section{Conclusion}

The current review highlights the relationship between sleep and athletes and the multiple factors that may influence athletes' sleep behavior. The relationship between sleep and varying hormonal markers is highlighted in the literature; however, 
further research is required to better understand how these interact to impact on athletic performance. Studies focusing on sleep loss and cognitive performance have shown cognitive functions to decrease, which could have a detrimental effect on sports that require high levels of cognitive functioning. A range of factors also combine to negatively influence sleep in athletes, with an increased incidence of sleep impairments occurring around competition. The area of napping and athletic performance remains underrepresented in the current literature, which, given the anecdotal prevalence of napping in athletes, is an area that requires more in-depth investigation. Sleep hygiene interventions have generated positive results in improving sleep indices in previous research, offering a practical tool for coaching staff and practitioners to use. Furthermore, sleep extension protocols, nutritional interventions, and the implementation of meditation and relaxation strategies may also be implemented by coaching staff and practitioners to assist with sleep in athletes. The current review highlights the importance for the need to investigate sleep in the elite athlete population. Given the fact that sleep provides a number of both psychologically and physiologically important functions that facilitate the recovery process, ${ }^{76}$ a greater understanding of strategies to improve sleep is central to future research in elite athletes.

\section{Disclosure}

The authors report no conflicts of interest in this work.

\section{References}

1. Argus C, Driller M, Ebert T, Martin D, Halson S. The effects of 4 different recovery strategies on repeat sprint-cycling performance. Int $J$ Sports Physiol Perform. 2013;8(5):542-548.

2. Coffey V, Leveritt M, Gill N. Effect of recovery modality on 4-hour repeated treadmill running performance and changes in physiological variables. J Sci Med Sport. 2004;7(1):1-10.

3. Leeder J, Glaister M, Pizzoferro K, Dawson J, Pedlar C. Sleep duration and quality in elite athletes measured using wristwatch actigraphy. J Sports Sci. 2012;30(6):541-545.

4. Juliff L, Halson S, Peiffer J. Understanding sleep disturbance in athletes prior to important compeititons. J Sci Med Sport. 2015;18(1):13-18.

5. Halson S. Sleep and the elite athlete. Sports Sci Exch. 2013;26(113): $1-4$.

6. Venter R. Role of sleep in performance and recovery of athletes: a review article. S Afr J Res Sport Phys Educ Recreation. 2012;34(1):167-184.

7. Kosmadopoulos A, Sargent C, Darwent D, Zhou X, Roach G. Alternatives to polysomnography (PSG): a validation of wrist actigraphy and a partial-PSG system. Behav Res Methods. 2014;46(4):1032-1041.

8. Mack DC, Patrie JT, Suratt PM, et al. Development and preliminary validation of heart rate and breathing rate detection using a passive, ballistocardiography-based sleep monitoring system. IEEE Trans Inf Technol Biomed. 2009;13(1):111-120.

9. McCall W, Erwin C, Edinger J, Krystal A, Marsh G. Ambulatory polysomnography: technical aspects and normative values. J Clin Neurophysiol. 1992;9(1):68-77.
10. Roky R, Herrera C, Ahmed Q. Sleep in athletes and the effects of Ramadan. J Sports Sci. 2012;30(1):S75-S84.

11. Halson S. Sleep in elite athletes and nutritional interventions to enhance sleep. Sports Med. 2014;44(1):13-23.

12. Kushida C, Littner M, Morgenthaler T, et al. Practice parameters for the indications for polysomnography and related procedures: an update for 2005. Sleep. 2005;28(4):499-520.

13. Ancoli-Israel S, Cole R, Alessi C, Chambers M, Moorcroft W, Pollak C. The role of actigraphy in the study of sleep and circadian rhythms. Sleep. 2003;26(3):342-392.

14. Sadeh A. The role and validity of actigraphy in sleep medicine: an update. Sleep Med Rev. 2011;15(4):259-267.

15. Driller M, McQuillan J, O'Donnell S. Inter-device reliability of an automatic-scoring actigraph for measuring sleep in healthy adults. Sleep Sci. 2016;9(3):198-201.

16. Driller M, O’Donnell S, Tavares F. What wrist should you wear your actigraphy device on? Analysis of dominant vs. non-dominant wrist actigraphy for measuring sleep in healthy adults. Sleep Sci. 2017;10(3):132-135

17. Sadeh A, Hauri P, Kripke D, Lavie P. The role of actigraphy in the evaluation of sleep disorders. Sleep. 1995;18(4):288-302.

18. Kushida C, Chang A, Gadkary C, Guilleminault C, Carrillo O, Dement W. Comparison of actigraphy, polysomnographic, and subjective assessment of sleep parameters in sleep-disordered patients. Sleep Med. 2001;2(5):389-396.

19. Dunican I, Murray K, Slater J, et al. Laboratory and home comparison of wrist-activity monitors and polysomnography in middle-aged adults. Sleep Biol Rhythms. 2018;16(1):85-97.

20. Caia J, Thornton H, Kelly V, et al. Does self-perceived sleep reflect sleep estimated via activity monitors in professional rugby league athletes? J Sports Sci. 2018;36(13):1492-1496.

21. Buysse D, Reynolds C, Monk T, Berman S, Kupfer D. The Pittsburg Sleep Quality Index: a new instrument for psychiatric practice and research. Psychiatry Research. 1989;28(2):193-213.

22. Johns M. A new method for measuring daytime sleepiness: the epworth sleepiness scale. Sleep. 1991;14(6):540-545.

23. Driller M, Mah C, Halson S. Development of the athlete sleep behavior questionnaire: a tool for identifying maladaptive sleep practices in elite athletes. Sleep Sci. 2018;11(1):37-44.

24. Samuels C, James L, Lawson D, Meeuwisse W. The athlete sleep screening questionnaire: a new tool for assessing and managing sleep in elite athletes. Br J Sports Med. 2016:50(7):418-422.

25. Thun E, Bjorvatn B, Flo E, Harris A, Pallesen S. Sleep, circadian rhythms, and athletic performance. Sleep Med Rev. 2015;23:1-9.

26. Souissi N, Souissi M, Souissi H, et al. Effect of time of day and partial sleep deprivation on short-term, high-power output. Chronobiol Int. 2008;25(6):1062-1076.

27. Reilly T, Edwards B. Altered sleep-wake cycles and physical performance in athletes. Physiol Behav. 2007;90(2-3):274-284.

28. Smith R, Guilleminault C, Efron B. Circadian rhythms and enhanced athletic performance in the national football league. Sleep. 1997;20(5):362-365.

29. Davenne D. Sleep of athletes - problems and possible solutions. Biol Rhythm Res. 2009;40(1):45-52.

30. Halson S. Nutrition, sleep and recovery. Eur J Sport Sci. 2008;8(2): 119-126.

31. Shapiro C, Bortz R, Mitchell D, Bartel P, Jooste P. Slow-wave sleep: a recovery period after exercise. Science. 1981;214(4526):1353-1254.

32. Weitzman E. Circadian rhythms and episodic hormone secretion in man. Annu Rev Med. 1976;27:225-243.

33. Gatti R, De Palo E. An update: salivary hormones and physical exercise. Scand J Med Sci Sports. 2011;21(2):157-169.

34. Lippi G, De Vita F, Salvagno G, Gelati M, Montagnana M, Guidi G. Measurement of morning saliva cortisol in athletes. Clin Biochem. 2009;42(9):904-906.

35. Cook C, Beaven C. Salivary testosterone is related to self-selected training load in elite female athletes. Physiol Behav. 2013;116:8-12. 
36. Beaven C, Gill N, Cook C. Salivary testosterone and cortisol responses in professional rugby players after four resistance exercise protocols. J Strength Cond Res. 2008;22(2):426-432.

37. Hansen S, Kvorning K, Sjøaard G. The effect of short-term strength training on human skeletal muscle: the importance of physioloigcally elevated hormone levels. Scand JMed Sci Sports. 2001;11(6):347-354.

38. Dattilo M, Antunes H, Medeiros A, et al. Sleep and muscle recovery: endocrinological and molecular basis for a new and promising hypothesis. Medical Hypotheses. 2011;77(2):220-222.

39. Filaire E, Sagnol M, Ferrand C, Maso F, Lac G. Psychophysiological stress in judo athletes during competitions. J Sports Med Phys Fit. 2001;41(2):263-268.

40. Bloom S, Johnson R, Park D, Rennie M, Sulaiman W. Differences in the metabolic and hormonal response to exercise between racing cyclists and untrained individuals. $J$ Physiol. 1976;258(1):1-18.

41. Fullagar H, Skorski S, Duffield R, Julian R, Bartlett J, Meyer T. Impaired sleep and recovery after night matches in elite football players. J Sports Sci. 2016;34(14):1333-1339.

42. Sargent C, Roach G. Sleep duration is reduced in elite athletes following night-time competitions. Chronobiol Int. 2016;33(6):667-670.

43. Shearer D, Jones R, Kilduff L, Cook C. Effects of competition on the sleep patterns of elite rugby union players. Eur J Sport Sci. 2015;15(8):681-686.

44. Juliff L, Halson S, Hebert J, Forsyth P, Peiffer J. Longer sleep durations are positively associated with finishing place during a national mulitday netball competition. J Strength Cond Res. 2018;32(1):189-184.

45. O’Donnell S, Bird S, Jacobson G, Driller M. Sleep and stress hormone responses to training and competition in elite female athletes. Eur $J$ Sport Sci. 2018;18(5):611-618.

46. Juliff L, Peiffer J, Halson S. Night games: physiological, neuroendocrine and pyschometric mechanisms to explain poor sleep. Int J Sports Physiol Perform. 2017;18:1-22.

47. Swinbourne R, Miller K, Smart D, Dulson D, Gill N. The effects of sleep extension on sleep, performance, immunity and physical stress in rugby players. Sports. 2018;6(2). pii:E42.

48. Balbo M, Leproult R, Van Cauter E. Impact of sleep and its disturbances on hypothalamo-pituitary-adrenal axis activity. Int $J$ Endocrinol. 2010;2010:759234.

49. Van Cauter E, Spiegel K, Tasali E, Leproult R. Metabolic consequences of sleep and sleep loss. Sleep Med. 2008;9(1):S23-S28.

50. Omisade A, Buxton O, Rusak B. Impact of acute sleep restricition on cortisol and leptin levels in young women. Physiol Behav. 2010;99(5):651-656.

51. Leproult R, Copinschi G, Buxton O, Van Cauter E. Sleep loss results in an elevation of cortisol levels the next evening. Sleep. 1997;20(10):865-870.

52. Knutson K, Spiegel K, Penev P, Van Cauter E. The metabolic consequence of sleep deprivation. Sleep Med Rev. 2007;11(3):163-178.

53. Taheri S, Lin L, Austin D, Young T, Mignot E. Short sleep duration is associated with reduced leptin, elevated ghrelin, and increased body mass index. PloS Medicine. 2004;1(3):e62.

54. Monteleone P, Maj M, Fusco M, Orazzo C, Kemali D. Physical exercise at night blunts the nocturnal increase of plasma melatonin levels in healthy humans. Life Sciences. 1990;47(22):1989-1995.

55. Escames G, Ozturk G, Baño-Otálora B, et al. Exercise and melatonin in humans: reciprocal benefits. J Pineal Res. 2012;52(1):1-11.

56. Buxton O, Frank S, L'Hermite-Baleriaux M, Leproult R, Turek F, Van Cauter E. Roles of intensity and duration of nocturnal exercise in causing phase delays of human circadian rhythms. Am J Physiology. 1997;273(3 Pt 1):E536-542.

57. Hobson J. Sleep is of the brain, by the brain and for the brain. Nature. 2005;437(7063):1254-1256.

58. Belenky G, Wesensten N, Thorne D, et al. Patterns of performance degradation and restoration during sleep restriction and subsequent recovery: a sleep dose-response study. J Sleep Res. 2003;12(1):1-12.

59. Stickgold R. Sleep-dependent memory consolidation. Nature. 2005;437(7063):1272-1278.
60. Zerouali Y, Jemel B, Godbout R. The effects of early and late night partial sleep deprivation on automatic and selective attention: an ERP study. Brain Res. 2010;1308:87-99.

61. Fullagar H, Skorski S, Duffield R, Hammes D, Coutts A, Meyer T. Sleep and athletic performance: the effects of sleep loss on exercise performance, and phyiological and cognitive responses to exercise. Sports Med. 2015;45(2):161-186.

62. Mograss MA, Guillem F, Brazzini-Poisson V, Godbout R. The effects of total sleep deprivation on recognition memory processes: a study of event-related potential. Neurobiol Learn Mem. 2009;91(4): 343-352.

63. Taheri M, Arabameri E. The effect of sleep deprivation on choice reaction time and anaerobic power of college student athletes. Asian J Sports Med. 2012;3(1):15-20.

64. Edwards B, Waterhouse J. Effects of one night of partial sleep deprivation upon diurnal rhythms of accuracy and consistency in throwing darts. Chronobiol Int. 2009;26(4):756-768.

65. Reyner L, Horne J. Sleep restriction and serving accuracy in performance tennis players, and effects of caffine. Physiol Behav. 2013;120:93-96.

66. Ben Cheikh R, Latiri I, Dogui M, Ben Saad H. Effects of one-night sleep deprivation on selective attention and isometric force in adolescent karate athletes. J Sports Med Phys Fitness. 2017;57(6):752-759.

67. Lastella M, Roach G, Halson S, Sargent C. Sleep/wake behaviours of elite athletes from individual and team sports. Eur J Sport Sci. 2015:15(2):94-100.

68. Lastella M, Roach G, Halson S, Martin D, West N, Sargent C. Sleep/ wake behaviour of endurance cyclists before and during competition. J Sports Sci. 2015;33(3):293-299.

69. Tuomilehto H, Vuorinen V, Penttilä E, et al. Sleep of professional athletes: underexploited potential to improve health and performance. J Sports Sci. 201735(7):704-710.

70. Sargent C, Lastella M, Halson S, Roach G. The impact of training schedules on the sleep and fatigue of elite athletes. Chronobiol Int. 2014;31(10):1160-1168.

71. Fullagar H, Skorski S, Duffield R, Meyer T. The effect of an acute sleep hygiene strategy following a late-night soccer match on recovery of players. Chronobiol Int. 2016;33(5):490-405.

72. Fullagar H, Duffield R, Skorski S, Coutts A, Julian R, Meyer T. Sleep and recovery in team sport: current sleep-related issues facing professional team-sport athletes. Int J Sports Physiol Perform. 2015;10(8):950-957.

73. Romyn G, Robey E, Dimmock J, Halson S, Peeling P. Sleep, anxiety and electronic device use by athletes in the training and competition environments. Eur J Sport Sci. 2016;16(3):301-308.

74. Oda S, Shirakawa K. Sleep onset is disrupted following pre-sleep exercise that causes large physiological excitement at bedtime. Eur J Appl Physiol. 2014;114(9):1789-1799.

75. Chennaoui M, Arnal P, Sauvet F, Léger D. Sleep and exercise: a reciprocal issue? Sleep Med Rev. 2015;20:59-72.

76. Nédélec M, Halson S, Abaidia A, Ahmaidi S, Dupont G. Stress, sleep and recovery in elite soccer: a critical review of the literature. Sports Med. 2015;45(10):1387-1400.

77. Kräuchi K. The thermophyiological cascade leading to sleep initiation in relation to phase of entertainment. Sleep Med Rev. 2007;11(6):439-451.

78. Hoshikawa M, Uchida S, Hirano Y. A subjective assessment of the prevelance and factors associated with poor sleep quality amongst elite japanese athletes. Sports Med. 2018;4:10.

79. Mah C, Kezirian E, Marcello B, Dement W. Poor sleep quality and insufficient sleep of a collegiate student-athlete population. J National Sleep Foundation. 2018;4(3):251-257.

80. O’Donnell S, Beaven C, Driller M. Sleep/wake behavior prior to and following competition in elite female athletes. Sport Sci Health. 2018;11(1):37-44

81. Pitchford N, Robertson S, Sargent C, Cordy J, Bishop D, Bartlett J. A change in training environment alters sleep quality but not quantity in elite australian rules football players. Int J Sports Physiol Perform. 2017;12(1):75-80. 
82. Dunican I, Higgins C, Jones M, et al. Caffeine use in a super rugby game and its relationship to post-game sleep. Eur J Sport Sci. Epub 2018 Feb 12.

83. Mah C, Mah K, Kezirian E, Dement W. The effects of sleep extension on the athletic performance of collegiate basketball players. Sleep. 2011;34(7):943-950.

84. Milewski M, Skaggs D, Bishop G, et al. Chronic lack of sleep is associated with increased sports injuries in adolescent athletes. J Pediatr Orthop. 2014;34(2):129-133.

85. Petit E, Mougin F, Bourdin H. A 20-min nap in athletes changes subsequent sleep architecture but does not alter physical performances after normal sleep or 5-h phase-advance conditions. Eur J Appl Physiol. 2014;114(2):305-315.

86. Waterhouse J, Atkinson G, Edwards B, Reilly T. The role of a short post-lunch nap in improving cognitive, motor, and sprint performance in participants with partial sleep deprivation. J Sports Sci. 2007;25(14):1557-1566.

87. Davies D, Graham K, Chow C. The effect of prior endurance training on nap sleep patterns. Int J Sports Physiol Perform. 2010;5(1):87-97.

88. Sargent C, Halson S, Roach G. Sleep or swim? Early-morning training severly restricts the amount of sleep obtained by elite swimmers. Eur J Sport Sci. 2014;14(1):310-315.

89. Thornton H, Duthie G, Pitchford N, Delaney J, Benton D, Dascombe B. Effects of a two-week high intensity training camp on sleep activity of professional rugby league athletes. Int J Sports Physiol Perform. 2016;12(7):928-933.

90. O'Donnell S, Beaven C, Driller M. The influence of match-day napping in elite female netball athletes. Int J Sports Physiol Perform. Epub 2018 Mar 15

91. Lastella M, Lovell G, Sargent C. Athletes' precompetitive sleep behavior and its relationship with subsequent precompetitive mood and performance. Eur J Sport Sci. 2014;14(Suppl 1):123-130.

92. Mastin D, Bryson J, Corwyn R. Assessment of sleep hygiene using the sleep hygiene index. J Behav Med. 2006;29(3):223-227.

93. Lacks P, Rotert M. Knowledge and practice of sleep hygiene techniques in insomniacs and good sleepers. Behav Res Ther. 1986;24(3):365-368.
94. Kakinuma M, Takahashi M, Kato N, et al. Effect of brief sleep hygiene education for workers of an information technology company. Ind Health. 2010;48(6):758-765.

95. Nishinoue N, Takano T, Kaku A, et al. Effects of sleep hygiene education and behavioral therapy on sleep quality of white-collar workers a randomized controlled trial. Ind Health. 2012;50(2):123-131.

96. Sousa I, Araujo J, Azevedo C. The effect of a sleep hygiene education program on the sleep-wake cycle of Brazilian adolescent students. Sleep Biol Rhythms. 2007;5(4):251-258

97. Gebhart C, Erlacher D, Schredl M. Moderate exercise plus sleep education improves self-reported sleep quality, daytime mood, and vitality in adults with chronic sleep complaints: a waiting list-controlled trial. Sleep Disord.2011; 2011:809312.

98. Fullagar H, Skorski S, Duffield R, Meyer T. The effect of an acute sleep hygiene strategy following a late-night soccer match on recovery of players. Chronobiol Int. 2016;33(5):1-16.

99. O’Donnell S, Driller M. Sleep-hygiene education improves sleep indices in elite female athletes. Int J Exerc Sci. 2017;10(4): $522-530$

100. Duffield R, Murphy A, Kellett A, Reid M. Recovery from repeated on-court tennis sessions: combining cold-water immersion, compression, and sleep interventions. Int J Sports Physiol Perform. 2014;9(2):273-282.

101. Van Ryswyk E, Weeks R, Bandick L, et al. A novel sleep optimisation program to improve athletes' well-being and performance. Eur J Sport Sci. 2017;17(2):144-151.

102. Jarraya M, Jarraya S, Chtourou H, Souiss, N, Chamari K. The effect of partial sleep deprivation on reaction time and the attentional capacities of the handball goalkeeper. Biol Rhythm Res. 2013;44(3).

103. Scott JP, McNaughton LR, Polman RC. Effects of sleep deprivation and exercise on cognitive, motor performance and mood. Physiol Behav. 2006;87(2):396-408.

104. Richmond LK, Dawson B, Hillman DR, Eastwood PR. The effect of interstate travel on sleep patterns of elite Australian rules footballers J Sci Med Sport. 2004;7(2);186-196.
Nature and Science of Sleep

\section{Publish your work in this journal}

Nature and Science of Sleep is an international, peer-reviewed, open access journal covering all aspects of sleep science and sleep medicine, including the neurophysiology and functions of sleep, the genetics of sleep, sleep and society, biological rhythms, dreaming, sleep disorders and therapy, and strategies to optimize healthy sleep. The manuscript

\section{Dovepress}

management system is completely online and includes a very quick and fair peer-review system, which is all easy to use. Visit http://www. dovepress.com/testimonials.php to read real quotes from published authors. 